\title{
Trabajadora/e/s Sociales como sujetos políticos, una apuesta desde la reconceptualización latinoamericana
}

\author{
Social workers as political subjects, \\ a bet from the Latin American reconceptualization
}

\author{
HAIDER ESTEBAN BAUTISTA JOAQUI \\ Trabajador Social, Fundación Universitaria Juan de Castellanos, Tunja, Colombia. \\ hbautista@jdc.edu.co Orcid: https://orcid.org/0000-0003-4336-059 \\ JOSEPH VICENT CASTILLO NIÑO \\ Estudiante de Trabajo Social, Universidad Industrial de Santander, Bucaramanga, Colombia. \\ joseph2162782@correo.uis.edu.co Orcid: https://orcid.org/0000-0001-5576-038X
}

Resumen: El presente artículo pretende evidenciar algunas reflexiones sobre la necesidad del profesional en Trabajo Social como sujeto político en la cotidianidad ante la arremetida del modelo neoliberal. El objetivo fue establecer la relación entre el movimiento de reconceptualización y la construcción de un/a trabajador/a social como sujeto político acorde a la cuestión social. Se empleó una revisión bibliográfica de carácter cualitativa en diversas bases de datos y mediante múltiples buscadores académicos. Se presenta el contexto socio-histórico del proceso de la reconceptualización en Latinoamérica. Sumada una búsqueda sobre las implicaciones de ser sujeto social y la comprensión de la cuestión social de cara a nuevas representaciones de la desigualdad social. Luego, una articulación y reflexión de las categorías señaladas anteriormente dando un apartado de discusión donde son expuestos algunos argumentos que sustentan el objetivo central de la investigación. A manera de conclusión, se destaca la necesidad de ser sujeto político desde la formación y ejercicio profesional frente a las nuevas representaciones de la cuestión social en concordancia con la vigencia de los aportes realizados por el movimiento de la reconceptualización (1960-1970). Se finaliza la discusión con una invitación para ampliar y fortalecer el área de investigación como una apuesta ético-política.

Palabras clave: Trabajo Social, reconceptualización, sujeto político, cuestión social, emancipación.

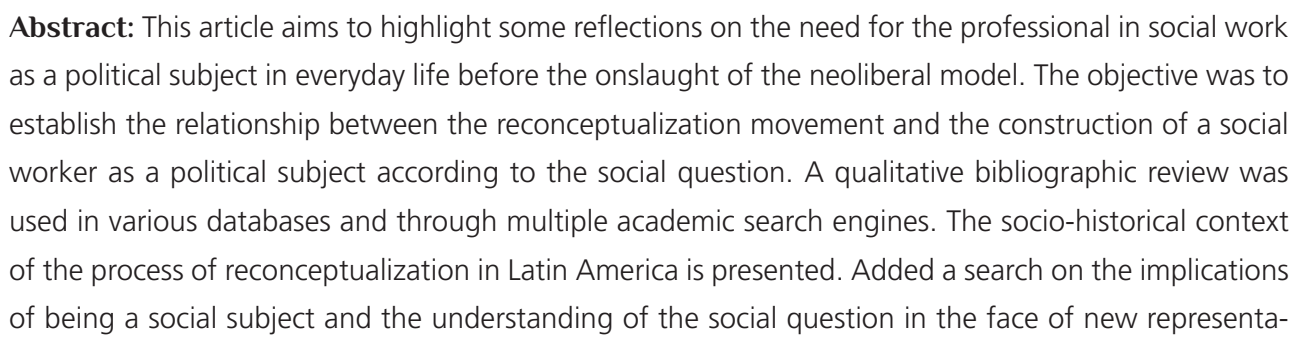


tions of social inequality. Then, an articulation and reflection of the categories indicated above, giving a discussion section where some arguments that support the central objective of the research are exposed. In conclusion, the need to be a political subject from training and professional practice is highlighted in the face of new representations of the social question in accordance with the validity of the contributions made by the reconceptualization movement (1960-1970). The discussion ends with an invitation to expand and strengthen the research area as an ethical-political commitment.

Keyword: Social work, reconceptualization, political subject, social issue, emancipation.

\section{INTRODUCCIÓN}

En la actualidad, Trabajo Social se encuentra en jaque debido a la modernidad y la imposición del modelo capitalista en los países latinoamericanos, donde la educación es estandarizada y privatizada con el fin de eliminar el pensamiento crítico que afecta notablemente a este sistema económico (López y Flores, 2009). Producto de esto, se ve obstaculizado e invisibilizado el papel de las ciencias humanas, que se define como "apuntar a comprender las experiencias humanas y el mundo comunitario del cual formamos parte" (Barragán y Torres, 2017, p. 55). De la misma forma, Trabajo Social no es ajeno a esto, según Federación Internacional de Trabajadores Sociales -FITS- (2014), se considera como una profesión que:

promueve el cambio y el desarrollo social, la cohesión social y el fortalecimiento y la liberación de las personas. Principios de la justicia social, los derechos humanos, la responsabilidad colectiva y el respeto a las diversidades son fundamentales para el Trabajo Social. Sustentado por las teorías del propias, ciencias sociales, humanidades y los conocimientos indígenas, el Trabajo Social involucra a las personas y estructuras para hacer frente a desafíos de la vida y mejorar el bienestar... (párr.1)

Acorde a lo anterior, la actuación de nuestra profesión está situada y enfocada en la apuesta de una construcción ético-política. El momento de acción profesional de Trabajo Social se denomina como "intervención", guiada por un actuar basado en un enfoque político cuyo fin es la vida digna humana (Malagón, 2012). Para lograr esto, la acción profesional debe ser contrahegemónica al modelo capitalista, enfocado en alta industrialización, el cual, según Pachón (2016), se enfoca en la eliminación del pensamiento divergente donde la única acción y conocimiento válido es el que es empleable para la consolidación del sistema.

El documento se encuentra dividido en cuatro momentos: en el primero, una revisión del contexto socio-histórico en el proceso de reconceptualización y sus aportes a la construcción de Trabajo Social crítico; el segundo, consideraciones sobre el ser sujeto político; en el tercero, una compresión de la cuestión social y su implicación en la profesión; en el cuarto, reflexiones referentes a las categorías expuestas anteriormente. Por último, un apartado dedicado a las conclusiones de todo el proceso investigativo realizado.

\section{ABORDAJE METODOLÓGICO}

El objetivo que guio la presente investigación fue el de establecer la relación entre el movimiento de reconceptualización y la construcción de un/a trabajador/a social como sujeto político acorde a la cuestión social. Para este caso, el objetivo general de investigación es posible de alcanzar mediante una revisión documental.

Este tipo de propuesta investigativa al criterio de Baena (2017), y Gómez (2010), está compuesta por la búsqueda exhaustiva en diversas fuentes bibliográficas como libros, revistas y demás elementos que puedan contribuir a dar respuesta a la pregunta de investigación, para lograr esto, es necesario partir de consideraciones interpretativas; la función de esto es brindar sentido, significados a la información recolectada de cara a la construcción de nuevo conocimiento producto del estudio. Cabe resaltar que no se trata solamente del acopio de la información plasmada de manera implícita en los materiales bibliográficos, es más que eso, busca generar reflexiones, consideraciones y críticas a partir de datos contenidos en los escritos de cara a una nueva perspectiva (Campo, 2017).

El sentido de este tipo de investigación es la construcción de un estado del arte referente a la temática abordada, para lograr esto, es necesario la identificación de los aportes realizados desde múltiples puntos de vista, las metodologías empleadas, las herramientas aplicadas, los enfoques investigativos que guiaron los procesos, los hallazgos y conclusiones (Martínez y Vargas, 2002).

El objetivo fue establecer la relación entre el movimiento de reconceptualización y la construcción de un/a trabajador/a 
social como sujeto político acorde a la cuestión social. Para lograr esto se partió de un enfoque hermenéutico, entendido como una visión reflexiva e interpretativa de los sentidos de los textos partiendo del contexto en el que fueron escritos, brindando una compresión de su contenido acorde a su historicidad y condiciones específicas, sumada a la perspectiva de Ricoeur como una propuesta para la reinterpretación de los textos y documentos traspasando la intencionalidad del autor para dar un sentido al presente (Arráez, et al., 2006).

El acopio de información se realizó mediante una búsqueda minuciosa de palabras clave como: Trabajo Social, Cuestión Social y Reconceptualización en diversas bases de datos de mediano y alto impacto como SciELO, REDALYC, Dialnet, EBSO HOST, JSTOR y SCOPUS. Se emplearon buscadores académicos como Google Scholar y Mendeley sumado al dispuesto por la Universidad Industrial de Santander a sus estudiantes. Como resultado se obtuvieron 73 documentos acordes a la temática que rige el presente manuscrito. El rango de material bibliográfico correspondió desde 1976 con fechas de corte 2019. Se establecieron criterios de inclusión como; publicación de artículos en revistas con revisión de pares académicos, editoriales reconocidas por sus aportes al Trabajo Social y a las ciencias humanas. Por su parte, los de exclusión; escritos con poco desarrollo argumentativo sobre las categorías establecidas. Dando un total de 43 documentos empleables (Ver Tabla I).

La elaboración del escrito consistió en tres momentos; el primero, una fase heurística o la búsqueda exhaustiva de material bibliográfico pertinente para la investigación como la reconceptualización, la cuestión social y el sujeto político. El segundo, una fase hermenéutica, donde se dio la organización de la información recolectada en el momento ante-

\begin{tabular}{|lc|}
\hline \multicolumn{2}{|c|}{ Tabla I. Procedencia de la INFORMación } \\
\hline Libros & 28 \\
\hline Revistas colombianas & 6 \\
\hline Revistas extranjeras & 6 \\
\hline Otros & 2 \\
\hline Tesis & 1 \\
\hline
\end{tabular}

Fuente: elaboración propia.

rior, para ello, se emplearon matrices y fichas bibliográficas acorde a cada temática para el análisis y escritura de las categorías previamente establecidas -reconceptualizacion, sujeto político y cuestión social- y su relación entre ellas. Por último, el apartado de conclusiones generales de la revisión, incluyendo una invitación a las y los colegas de Trabajo Social a nivel internacional a fortalecer el área investigativa de la profesión cómo un compromiso ético político.

\section{RESULTADOS}

Para el análisis de la información recolectada se construyó una matriz categorial para la organización de los datos obtenidos mediante la revisión (Ver Gráfica 1). En ese caso, las categorías fueron los ejes que centraron la búsqueda acorde a los contenidos sobre la temática.

\subsection{Alcances de la reconceptualización}

Aunque este proceso de reconceptualización fue un hito dentro de la construcción de profesión con perspectiva crítica, se dieron algunos antecedentes como el caso de Mary E. Richmond (Aranda, 2011).

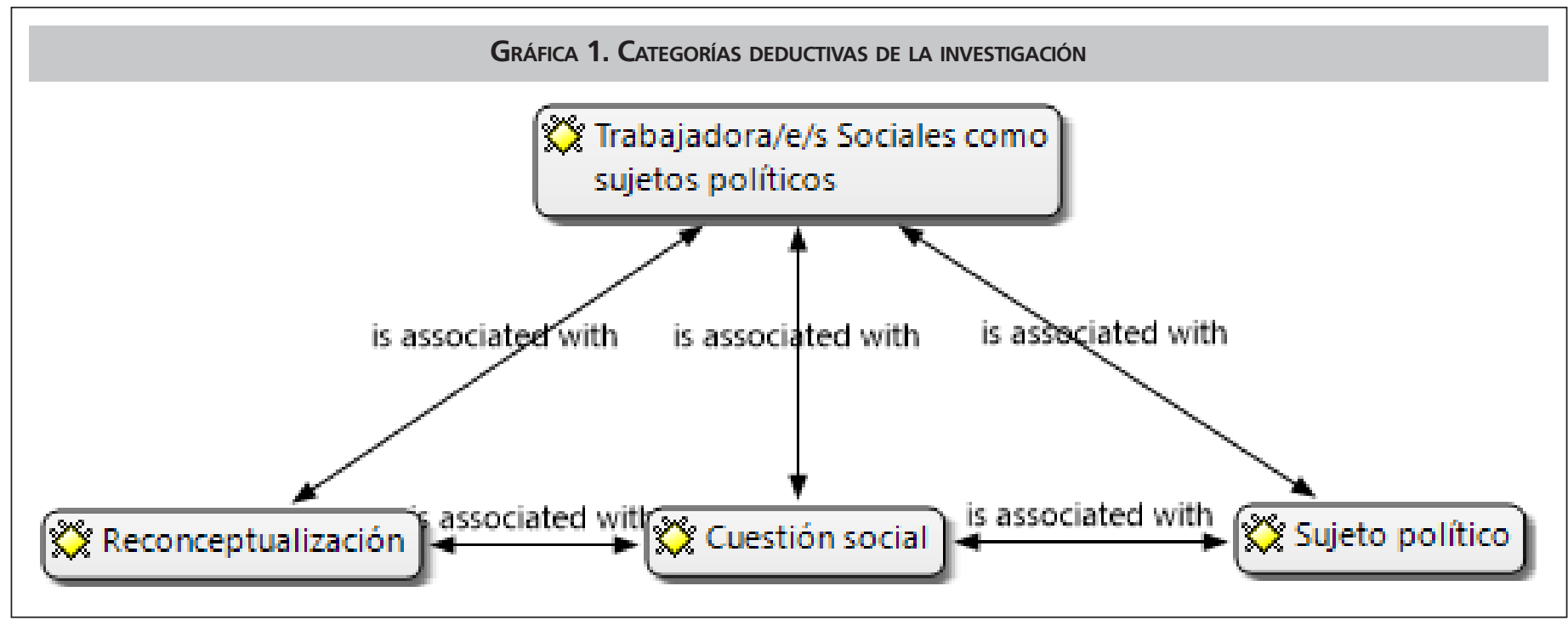

Fuente: Elaboración propia mediante Atlas Ti®versión 7.1.7. 
El desarrollo histórico de la profesión ha sido objeto de múltiples debates dentro de los espacios académicos de toda Latinoamérica. En el caso de Malagón (2012), establece una etapa previa a este proceso, que denomina como la "preconceptualización", consta de dos momentos, el primero, llamado como periodo filosófico, donde el accionar estaba guiado por la moral de la iglesia católica, el segundo, conocido como el periodo científico, el cual consistió en la intervención social basada en conocimiento -de carácter positivista-y posterior a esto la reconceptualización. Por su parte, Ander Egg (1997), sostiene que la profesión atravesó tres grandes etapas; asistencia social, servicio social ${ }^{1}$ y por último, Trabajo Social.

Aunque existen diversas perspectivas sobre las transformaciones dentro de la profesión, claramente "Existe un consenso evidente en el reconocimiento de la Reconceptualización como movimiento fuertemente 'influenciado' o determinado por el contexto político de crisis que se vivió tanto a nivel mundial como latinoamericano durante las décadas de 1960 y 1970" (Quintero, 2018, p. 184). Uno de los acontecimientos que impulsó este movimiento fue el de la revolución cubana sumado a las constantes movilizaciones sociales en el marco de la guerra fría en el hemisferio. Dicho escenario estuvo integrado por múltiples representaciones sociales en medio de una disputa económica, social y cultural entre los dos grandes bloques. En este plano de alta conflictividad, el Trabajo Social latinoamericano ingresó en un momento de autorreflexión, como lo evidencia Quintero (2018):

El contexto revolucionario latinoamericano que determina la profesión, traducido sin mediaciones al movimiento de la Reconceptualización, hizo que se presentaran fuertes límites de orden 'voluntarista', 'politicista' y 'mesiánico', evidentes en las pretensiones profesionales de "agentes de cambio" y "transformación social". (p.195)

En esta propuesta la profesión es llamada la reactivación de los vínculos sociales y prácticas comunitarias contrahegemónicas, para lograr estos fue necesario la integración de conocimientos provenientes de otras ciencias sociales. De igual forma, se dio la construcción de la especificidad y junto a ellos el repensar las acciones que desde la profesión se pueden realizar para promover dicho cambio y transformación social. No es distante la perspectiva sobre la reconceptualización por parte de Alayón (2015) donde afirma que:

Los trabajadores sociales comenzamos a identificar y reconocer el origen de la desigualdad social en las relaciones de dominación vigentes en la sociedad, cuestionando las propuestas de integración al medio de los "desadaptados" o "marginados", propias de aquel pensamiento "modernizador" y de las concepciones teóricas funcionalistas, propuestas éstas provenientes de la óptica de entender como justo y adecuado el modelo imperante. (p. 13)

Producto de esta transformación ideológica se ponen en tela de juicio las acciones caritativas fundamentadas en el asistencialismo de carácter religioso. Se pasó a un plano de cambio social activo, reconociendo los aportes de los mismos sujetos involucrados en el proceso de intervención dejando a un lado la imposición por parte del profesional. Uno de los principales avances de la reconceptualización según Vélez (2003) es que:

aboga por la producción de lecturas propias y específicas sobre la realidad social. Se fortalece la relación del Trabajo Social con las Ciencias Sociales y aparece un marcado interés por fundamentar teóricamente la profesión, siguiendo el modelo que las corrientes marxistas. (p.135)

Ante la carencia de teorías propias, el movimiento de reconceptualización cuestiona sus fundamentos trayendo consigo una transición de profesión operativa a profesión con fundamentos teóricos y metodológicos construidos desde la especificidad. Este cambio se vio fuertemente influenciado por diversas corrientes de pensamiento resaltando la participación del marxismo y su concepción de pensamiento crítico expuesto por Aguirre (2019) como:

aquel que va a contracorriente del pensamiento dominante, marchando de distintas maneras en sentidos opuestos y luego divergentes de este último, y utilizando diversos procedimientos epistemológicos para tomar distancia y alejarse de las falsas evidencias y de los segados y para nada inocentes teoremas, afirmaciones y explicaciones del mundo y de la realidad que nos da ese pensamiento dominante establecido. (p. 8)

Dicha propuesta de pensamiento crítico alimentó las discusiones dentro del movimiento de reconceptualización de cara a la situación de profunda desigualdad experimentada en el continente. La herencia de este momento se ve evidenciada en la definición de Trabajo Social presentada por Ander Egg (2003):

Modo de acción social superado de la asistencia social y del servicio social. El Trabajo Social tiene una función de

1 Cabe resaltar que el análisis fue realizado particularmente en el caso latinoamericano, diferenciado social, económica y culturalmente del contexto europeo 
concientización, movilización y organización del pueblo, para que, en un proceso de promoción del autodesarrollo interdependiente, individuos, grupos y comunidades realizando proyectos de Trabajo Social, insertos críticamente y actuando en sus propias organizaciones, participen activamente en la realización de un proyecto político que signifique el tránsito de una situación de dominación y marginalidad a otra de plena participación del pueblo. (p. 78)

Este movimiento es fruto de una crisis del modelo capitalista, además de una fuerte inspiración de la teoría marxista basados en materialismo histórico y dialéctico, generando así contradicciones en sectores conservadores del Trabajo Social y la nueva tendencia de análisis de la realidad basada en las propuestas y planteamientos teóricos de Karl Marx (Quintero, 2014). Entendiendo este proceso como una transformación donde se originó el cuestionamiento de la realidad de la profesión, una nueva mirada reflexiva y crítica ante la preparación académica en función del capitalismo, atribuyendo las problemáticas sociales a los individuos y no a la desigualdad provocada por el sistema dominante (Malagón, 2012). De acuerdo con lo planteado por Malagón (2012):

Se podría decir que la reconceptualización intentó construir el Trabajo Social como una profesión revolucionaria. Se presumía que los trabajadores sociales, sin dejar sus cargos en las organizaciones de bienestar social, podrían subvertir el sistema desde su interior aprovechando las fisuras que existieran. (p. 299)

Dicha apuesta de construcción del Trabajo Social estuvo evocada en una renovación profesional, producto de un cuestionamiento de los procesos metodológicos, la fundamentación teórica y el carácter político-ideológico, sin olvidar las herramientas y técnicas empleadas en ese momento histórico (Quintero, 2014). El autor Palma (1977), establece tres grandes características de la reconceptualización:

- La reconceptualización brota cuando el descontento con la función del servicio social tradicional se cruza con la elevación continental de la expectativa de transformación social.

- El movimiento se desarrolla primeramente en los países que logran una cierta agudización de la lucha de clases.

- Los grupos reconceptualizadores se concentran sobre las universidades o se ligan a las iglesias (p. 87)
Los cambios no solo se dieron en aspectos teóricos y metodológicos dentro de la profesión. También tuvo incidencia en la dimensión axiológica y en los principios como profesión, como lo evidencia Parra (2003):

durante el movimiento de reconceptualización el Trabajo Social, al cuestionar sus orígenes antimodernos y conservadores- comienza a dialogar con el proyecto de modernidad, en la medida en que sus análisis, debates y propuestas comienzan a incorporar las categorías de universalidad, individualidad y autonomía en el camino a la emancipación de género humano (p.83).

Este proceso cuestiona la naturalidad de las desigualdades sociales, económicas y culturales. Dejando al lado la armonización de clases que se gestaba mediante las acciones caritativas disminuyendo el descontento social reduciendo los movimientos obreros cuyo fin es el reconocimiento de la institucionalidad y la recristianización para tomar un papel político transformador de la realidad. En síntesis, la reconceptualización se basó en un movimiento antipositivista, un cuestionamiento de los conceptos básicos de la profesión dando como resultado la resignificación de los mismos, simultáneamente, Trabajo Social se integraba en los debates dentro de las ciencias sociales que se estaban gestando en la época en Latinoamérica producto de la desigualdad consolidada por el modelo de acumulación de capital (Samperio, De Marinis y Verón, 2004).

Aunque la profesión históricamente ha sido feminizada, gran parte de la producción académica referente a la temática es masculina. Esto evidencia una invisibilización de los aportes académicos realizados por las mujeres. La cuestión de género es un tema de interés, producto de la reconceptualización, el reconocimiento de la diversidad y las contribuciones desde múltiples perspectivas en la construcción de un nuevo Trabajo Social Crítico situado y emancipador.

\subsection{La cuestión social}

La cuestión social se encuentra en el epicentro de las discusiones del Servicio Social ${ }^{2}$ - Trabajo Social contemporáneo en Latinoamérica. El debate sobre los alcances del concepto, aporta a la construcción de la profesión en el ámbito epistemológico, metodológico con miras al proyecto ético político.

Netto (2003), menciona que el concepto comenzó a ser empleado debido a la ola masiva de pauperización, especialmente en Europa Occidental en el siglo XVII producto de la industrialización para la cual, la clase obrera y trabajadora no

2 Se hace referencia al nombre que ha tomado la profesión en Brasil. 
estaba preparada y muchos menos se contaba con las políticas sociales necesarias para atender dicha problemática; el concepto ha tenido relación estrecha con el capitalismo y la instauración de dicho sistema a nivel mundial, y precisamente es un término social debido a que describe la desigualdad que estos acontecimientos generaron entre las clases sociales. Acorde al anterior planteamiento, lamamoto (2003) entiende y explica la cuestión social como:

El conjunto de expresiones de las desigualdades de la sociedad capitalista madura, que tiene una raíz común: la producción social es cada vez más colectiva, el trabajo se torna cada vez más social, mientras que la apropiación de sus frutos se mantiene monopolizada por una parte de la sociedad. (p. 13)

Por su parte, Pereira (2003) destaca que "sujetos situados estratégicamente asumieron papeles políticos fundamentales en la transformación de necesidades sociales en cuestiones" (p. 73). Por ello, como plantea Guerra (2017), la profesión de Trabajo Social se va desarrollando en el marco de la cuestión social producto de la reproducción capitalista, dichas representaciones son particulares de una sociedad burguesa que genera desigualdades sociales. Aunque la profesión esté en la búsqueda de una superación de lo denominado como "cuestión social" dicha emancipación no significa el fin mismo del Trabajo Social, debido a que la sociedad siempre se ve envuelta de diferentes necesidades y problemáticas producto de las condiciones históricas propias de cada tiempo (Netto, 2003). Dicha idea se respalda en que "la cuestión social implica, al mismo tiempo, captar las múltiples formas de presión social, de invención y de reinvención de la vida construidas en el cotidiano" (Iamamoto, 2003 p. 42). Es así como el término presenta un espacio para la discusión dentro de la profesión, según Vélez (2003):

reconociendo la territorialidad y temporalidad de los conflictos, las alianzas y rupturas que se establecen entre los actores y la forma en que sus experiencias y vivencias inciden en la construcción de la realidad. La pluralidad de identidades y demandas que habitan en los procesos comunitarios es central para el desarrollo de teorías, metodologías o proyectos sociales. (p. 67)

Es una necesidad volver la cotidianidad una categoría de análisis para comprender la realidad subjetiva de las personas para identificar las representaciones de las desigualdades específicas de cada sujeto. Además, se han creado debates de si se debe o no de hablar de una nueva cuestión social (Carballeda, 2002). La interpretación de una nueva cuestión social está ligada a la aparición de nuevas problemáticas no estudiadas y/o intervenidas. La razón de esto es el reconocimiento de las singularidades de cada país, que ante la simple perspectiva parecen iguales, son todo lo contrario, poseen características propias del contexto económico, social y cultural irrepetible en otro escenario. Por lo tanto, no hay espacio para establecer generalidades sino particularidades.

\subsection{El ser sujeto político}

El filósofo griego Aristóteles, en su libro "La Política" hace referencia al hombre como animal político por naturaleza conocido como "zoon politikón", y un espacio relacional, en este caso, la polis (Aristóteles, 1934). El sujeto político, desde esta perspectiva aristotélica, es un animal racional, usa dicha razón para organizarse en sociedad, además, cuenta con la capacidad de expresar sentimientos y valores (Huici y Dávila, 2006). Por su parte, Fernández (2009), lo define como:

Un hombre de convicciones, ideales, con capacidad reflexiva y crítica, que posea el misterio del carisma, y sobre todo con un gran sentido de servicio social, en pro del bien común, encauzado en la construcción de ciudadanías y sociedades conscientes y dueñas de sus propias realidades. (p. 8)

Es entonces el sujeto político parte indispensable e inherente de la política, entendida según Jiménez (2012) como: "un escenario de disputa y antagonismo civilizado, donde se plantean diferentes posiciones y alternativas sobre la manera de entender y resolver los conflictos sociales" (p. 6). Estas personas -pasando a un breve lapso a corrientes marxistaposeen una conciencia de clase, la priorización de intereses sociales contrapuestos a las élites económicas y políticas tanto a nivel local como internacional. Del mismo modo, hace referencia a la construcción de identidades dueñas de su propia realidad. Para lograr la emancipación es necesario ser un sujeto político, que actúe frente a las desigualdades. En este sentido, Fernández (2009), plantea que es "aquel ser humano capaz de asumir el rol y los retos, que se imponen o que las estructuras sociales les han impuesto" (p.1). Por ello, se hace necesario tener en cuenta lo planteado por Martínez (2008), "hablar del sujeto político en la modernidad, siempre remite al "soberano" capaz de situarse por encima de los intereses particulares con el propósito de mantener un orden social integrado, racional y universal" (p. 73). 
Mientras que Bedin (2000), evidencia la dificultad de que todos los derechos sociales sean garantizados en su totalidad, una de las causas es la incapacidad de actuar, pensar y valorar, pensarse a sí misma la sociedad de cara a las desigualdades. Esto es producto de lo dialéctica que es la sociedad. Se encuentra en constante cambio, con contradicciones e interés contrapuestos. Si la sociedad está imposibilitada, para el estado que debería ser el garante de dichos derechos, bajo la perspectiva neoliberal en la que está inmersa, se complejiza, ya que existen las necesidades y existen los derechos, pero la tercerización del cumplimiento de ellos hará más difícil saber a quién se le debe exigir el goce de los mismos. Más aún cuando existen otros factores de gran influencia la búsqueda de intereses personales por encima de los colectivos por parte de los altos dirigentes.

Se hace imperioso, evidenciar que, dentro de las dinámicas de los sujetos políticos, hay otra serie de términos alrededor de él, uno de ellos es el poder político, el cual según Arendt (1997) "emana del contrato social y no hace referencia a una experiencia política sino a una experiencia social orientada asegurar la esfera de los intereses privados" (p. 89). Lo que evidencia el fortalecimiento del capitalismo y neoliberalismo. Cabe resaltar que el poder político permite asegurar los intereses traducidos en acumulación de capital y relaciones de dominación.

\section{DISCUSIÓN}

El sentido del presente apartado es la correlación de las categorías abordadas anteriormente como lo son; la reconceptualización, la cuestión y el sujeto político, con ello, generar un diálogo y reflexiones en torno a la necesidad del trabajador social como un sujeto político en lo contemporáneo como una respuesta ante las nuevas representaciones de la desigualdad denominadas como "cuestión social".

Una de las reflexiones de este movimiento fue que la actuación del Trabajo Social no se puede desligar de la acción política debido a que "como profesión, tiene una necesaria dimensión política, por encontrarse íntimamente articulado con las relaciones de poder de la sociedad" (lamamoto, 2003:72). Esta versión es respaldada por Valencia (2014) donde manifiesta que:

la dimensión política y ética a partir de las concepciones tanto histórica como de totalidad, teniendo en cuenta las implicaciones de la neutralidad política y la ética tomista y neo-tomista propia del positivismo y neo-positivismo que se ha instalado y permanecido en la profesión desde su fundación legal en Colombia. (p. 117)
El cambio del positivismo a corrientes histórico-críticas introdujo una perspectiva ideológica y política en el Trabajo Social. A causa de esto, la acción profesional no puede desligarse de lo ético-político, ni de lo económico o lo cultural; es decir, no mirar la realidad a partir de lo que Cabaluz (2015), denomina como el recorte de la realidad, limitándose a esferas inconexas que limitan la comprensión y el conocimiento de la misma. La reconceptualización trae consigo avances importantes para la construcción crítica y da inicios a un sujeto político como lo manifiesta Vélez (2003):

le confiere a la profesión un sustento eminentemente ideológico y su proceso de constitución se ve seriamente comprometido con una opción política, de liberación y transformación social, a favor de las clases oprimidas, encontrando en el metodologismo una vía o alternativa de acción profesional. (p.46)

Producto de lo expuesto, se ensamblan la categoría de sujeto político y el abordaje de la cuestión social en la construcción de una nueva realidad de los marginados, invisibilizados y excluidos por el sistema, con el fin de generar conjuntamente una transformación de la vida cotidiana en todas las esferas tanto políticas como económicas y sociales. Acorde a esto, Marín y Aguirre (2013), afiman que:

al papel de los trabajadores sociales en el contexto económico, político y social del país, el cual se asumía desde el compromiso, reflejado en las movilizaciones, en los discursos y en las ansias por generar el cambio desde la base, es decir, desde los más pobres y excluidos de la sociedad y con ello lograr condiciones de igualdad, equidad y bienestar, para las comunidades desde lo individual y colectivo. (p.281)

Lo planteado anteriormente sitúa a Trabajo Social al lado de los sectores populares y oprimidos. Si bien el ideal social apuntaría a que todo individuo fuese un sujeto político, existen dinámicas y características contextuales que no lo permiten o lo dificultan. En este sentido, cada intervención realizada desde la profesión, bajo una dimensión ético política, está inmerso en un actuar político (Kisnerman, 1998). Razón por la cual, el profesional no es visto como un tercero dentro de la interacción con los sujetos sociales, sino que por el contrario debe ser y hacer parte de dichos procesos (Estrada, López y Posada, 1997). Con ello, respondiendo a dimensiones axiológicas, críticas, éticas y políticas.

Se considera el papel del Trabajo Social como una práctica educativa que entiende el conocimiento como herramienta 
para la lucha y la construcción de una nueva sociedad. Así, el movimiento de reconceptualización brinda las bases para la construcción de un Trabajo Social como sujeto político, pasó de ser una profesión-disciplina enfocada en la consolidación del sistema mediante atenciones paliativas de carácter positivista y "se convirtió en pedagogía de lo emancipatorio, y los trabajadores sociales, en revolucionarios" (Malagón, 2012, p. 18). En este plano, los cuestionamientos epistemológicos-metodológicos se dieron constantemente como lo afirma Vélez (2003):

Reconceptualización (décadas de los sesenta y setenta) como movimiento de crítica al Trabajo Social tradicional y al conjunto de las teorías funcionalistas y psicologistas mediante las cuales la profesión explica y actúa en lo social. Abogan por la descentralización y desinstitucionalización de la práctica profesional, la democratización y el fortalecimiento del trabajo en equipo. (p. 77)

A raíz de esto, la relación que se establece dentro del reconocimiento de la diferencia subjetiva, esto permite a la profesión enfocar su aprendizaje y práctica a el análisis crítico desde la diversidad de saberes. La relevancia de esto radica en la capacidad de auto reconocerse como partícipe político, el cual, es capaz de generar conocimiento a partir de su relación con la realidad. De igual manera, llevar a cabo procesos desde y para los sujetos y comunidades de forma tal que se acoplen y respondan a las necesidades que exige un determinado contexto.

Para la construcción de un trabajador como sujeto político es imprescindible su participación en los movimientos sociales en América latina como una apuesta en la construcción de una "hegemonía popular desde abajo" aumentando la participación de los denominados como "pobres"; de allí surge una lucha constante contra el capital (Soto, 2012). La participación contribuye al conocimiento de los nuevos patrones y representaciones que tiene la cuestión social en contextos específicos e históricos.

Un logro obtenido mediante la reconceptualización es un trabajo social militante político, trabajando con, para y desde las bases sociales, reconociendo lo multifacético de los movimientos sociales; resaltando la importancia de la formación política e ideológica de las personas excluidas por el capital debido a que estas organizaciones se forman en contraposición a la desigualdad social y económica, se constituyen como una respuesta, un enfrentamiento constante a un sistema excluyente (Zibechi, 2010). La reconceptualización da un carácter emancipatorio como lo afirma Malagón (2012)" constituye una cosmovisión que posibilita la interpretación crítica y holística de las formas de alienación que produce la sociedad capitalista" (p. 259). Por ende, un constante relacionamiento con las bases sociales y conocimiento de las problemáticas que afrontan, en otras palabras, la nueva cuestión social.

Así, construyendo "desde abajo" propuestas de trabajo contrahegemónicas y lazos comunitarios sumado a procesos de formación bajo los principios de la pedagogía crítica y emancipadora que significan resistencia ante la desigualdad y la exclusión social. Asimismo, este tipo de acciones son de carácter reflexivo en sus participantes, son el repensar la situación actual de desigualdad en la que se vive; por ello, el fin de la acción política es la transformación subjetiva e intersubjetiva en los colectivos para la creación de organizaciones "desde abajo", desde el pueblo, los oprimidos e invisibilizados (Torres, 2017). En el mismo sentido, Cademartori, Campos y Seiffer (2007), afirman que:

Un Trabajo Social crítico es un Trabajo Social que se enfrenta con su qué hacer en la búsqueda de la necesidad concreta de su acción. Es un Trabajo Social que busca actuar con conocimiento de causas y para ello no se detiene en la inmediatez de las formas, sino que busca trascenderlas. Es un Trabajo Social que se reconoce en su enajenación y busca tomar en sus manos las potencias históricas que tal enajenación le impone en el camino de la construcción de la comunidad de individuos libres: en el camino del socialismo. (p.20)

Como se plantea anteriormente, la comunidad y lazos comunitarios son una alternativa al capitalismo y colonialismo, según Torres (2013), reconociendo las intersubjetividades y la autonomía, especialmente en los pueblos originarios en diversos territorios a nivel nacional, un método de resistencia ante el capital y la destrucción de la cultura. Todo esto desde una perspectiva de género en una apuesta de actuación ética desde Trabajo Social, la integración de dicha visión transforma la percepción de las problemáticas, sus posibles soluciones gestadas con las personas involucradas (Romero, Casal y Contreras, 2017).

Aunque el ser sujeto político no es propio de una profesión específica, Trabajo Social no debe ser ajeno a esta posición debido a su constante acción e intervención en la transformación social de cara a la desigualdad producida por la consolidación del modelo capitalista en latinoamérica. Esto es respaldado por Netto (2017), quien precisa que "la profesión está hipotecada a la existencia de la "cuestión so- 
cial" más precisamente, a sus expresiones, antiguas y nuevas, cuando estas se tornan objeto de la intervención cohesiva del estado burgués" (p. 27). Es de aclarar que las acciones profesionales no se pueden desligar de las actividades cotidianas debido a que nos encontramos en un compromiso de transformación social de la realidad.

Ahora bien, lo mencionado anteriormente tiene una relación directa con el Trabajo Social contemporáneo de visión histórico-crítica, la razón de esto es que nuestra profesión-disciplina está enfocada en al abordaje y emancipación de las subalternidades, en ejercer labores pedagógicas en búsqueda de cambios de carácter local en una apuesta de modificación estructural, la construcción de poder popular, el cual, no se conforman ante la realidad tal y como se la quieren presentar, como aquello dado, sino que la cuestiona desde la radicalidad en miras a un objetivo emancipatorio y liberador.

\section{CONCLUSIONES}

Los aportes en la construcción de un Trabajo Social crítico producto del movimiento de reconceptualización en Latinoamérica (1960-1970) siguen vigentes. Los avances en el cuestionamiento del capitalismo y colonialismo dentro de la profesión son totalmente válidos y aplicables en la actualidad. Su contribución al proceso de emancipación social y construcción de una nueva sociedad situada desde los contextos y no ajenos a ellos. Asimismo, presenta un espacio de autonomía relativa en la actuación de los profesionales en búsqueda de la construcción de un proyecto ético político enfocado en el cambio verdaderos de las condiciones.

El proceso de reconceptualización trajo consigo el repensar desde las bases teóricas y epistemológicas en que se fundamenta la intervención de carácter conductual y positivista hasta los marcos metodológicos pasando a un momento de reflexión-acción dejando a un lado la aplicación de métodos sin cuestionar su verdadera utilidad en diversos contextos. De igual manera, las teorías y conocimientos provenientes de otras áreas de las ciencias humanas siguen siendo un respaldo, pero se inicia el proceso de crear conocimiento propio partiendo de la acción profesional.

El ser sujeto político se plantea como una necesidad para el/la trabajador/a social contemporáneo como partícipe de la realidad y no simplemente como un/a observador/a de la misma. Dentro de su quehacer, no solo cumple lo que su trabajo le demande, sino que incorpora transversalmente la necesidad de buscar el origen de las situaciones problema que aquejan al o a los sujetos sociales y dentro de su plan de acción articula y reconoce las estrategias necesarias para una transformación social, estos pilares de participación activa en los procesos de intervención, son producto de la reconceptualización, sin desconocer los desafíos institucionales a los que se pueda ver enfrentado para sobreponer los intereses personales por el bien común de la población atendida.

Las acciones del/a trabajador/a social deben estar guiadas por principios como: la emancipación, liberación, reconocimiento de las desigualdades socio-históricas, transformación social; igualmente, participación en los movimientos sociales por la construcción de una nueva realidad de los marginados, invisibilizados y excluidos por el sistema, una transformación de la vida cotidiana en todas las esferas tanto políticas como económicas y sociales. Así, identificar las nuevas representaciones que adopta la cuestión social producto de un modelo capitalista especialmente en el contexto latinoamericano, es entonces o la profesional en Trabajo Social quien debe mediar entre la realidad social y las problemáticas que pretende intervenir, frente a la realidad política y las formas de organización local, regional, nacional e internacional, enmarcados dentro del neoliberalismo, mismo sistema que por su naturaleza interpone unas barreras y limitantes dentro del quehacer profesional.

El Trabajo Social como profesión-disciplina no puede desligarse del reconocimiento de las desigualdades de género en la actualidad. En este sentido, debe establecer una perspectiva crítica entendiendo los mecanismos de opresión establecidos por la sociedad y las instituciones. Es menester reconocer los aportes realizados por las mujeres en la construcción de un Trabajo Social crítico acorde a la realidad social.

Por último, la invitación que se extiende, está encaminada al aumento y fortalecimiento de la investigación de carácter documental, enfocada en rescatar los aportes realizados con anterioridad en la profesión que han sido ignorados o invisibilizados por la misma academia o por barreras estructurales establecidas por el modelo capitalista, desconociendo su valor. Todo esto empleando un medio crítico-reflexivo cuyo fin sea una respuesta que originé fundamentos y estrategias ante la situación actual que enfrenta la profesión.

\section{REFERENCIAS BIBLIOGRÁFICAS}

Aguirre, C. (2019). Lecciones de teoría crítica. Bogotá, Colombia: Ediciones Desde Abajo.

Alayón, N. (2015). Trabajo Social Latinoamericano, a 40 años de la reconceptualización. Argentina: Espacio Editorial.

Ander Egg, E. (1997). Historia del Trabajo Social. Argentina: Editorial Lumen. 
Ander Egg, E. (2003). Diccionario de Trabajo Social. Argentina: Editorial Lumen.

Aranda, M. (2011). Contexto de la actividad y el pensamiento de Mary Richmond. Cuadernos de Trabajo Social, 24, $35-$ 45. https://doi.org/10.5209/rev_CUTS.2011.v24.36853

Arendt, H. (1997). Qué es la política. España: Paidós.

Aristóteles (1934). La Política (Pedro Abril. Trad.). España: Ediciones Nuestra Raza Madrid. (Obra original publicada en Siglo IV a. C)

Arráez, M., Calles, J., y Moreno de Tovar, L. (2006). La Hermenéutica: una actividad interpretativa. Sapiens, 7(2), 171-181. Recuperado de: https://www.redalyc.org/pdf/410/41070212. pdf

Baena, G. (2017). Metodología de la investigación. México: Grupo Editorial Patria.

Barragán, D. y Torres, A. (2017). La sistematización como investigación interpretativa crítica. Bogotá, Colombia: Editorial el Buho Ltda.

Bedin, G. (2000). Los derechos humanos y el neoliberalismo. Bogotá, Colombia: Cooperativa Editorial Magisterio.

Cabaluz, F. (2015). Entramando pedagogías críticas latinoamericanas. Notas teóricas para potenciar el Trabajo político-pedagógico comunitario. Primera edición, Chile: Editorial Quimantú.

Cademartori, F,. Campos, J. y Seiffer, T. (2007). Condiciones de Trabajo de los trabajadores sociales, hacia un proyecto profesional crítico. Buenos Aires, Argentina: Espacio Editorial

Campos, M. (2017). Métodos y técnicas de investigación académica fundamentos de investigación bibliográfica. Universidad de Costa Rica. Recuperado de: http:// www.kerwa.ucr.ac.cr/bitstream/handle/10669/76783/ Campos\%200campo,\%20Melvin. \%202017.\%20M\%C3\%A9todos\%20de\%20Investigaci\%C3\%B3n\%20 acad\%C3\%A9mica. \%20(versi\%C3\%B3n\%201.1).\%20 Sede $\% 20$ de $\% 200$ ccidente, $\% 20$ UCR.pdf? sequence $=1$

Carballeda, A. (2002). La intervención en lo social. Exclusión e integración en los nuevos escenarios sociales. Editorial Paidós. Buenos aires.

Estrada, P., López, R. D. y Posada, F.A. (1997). Cibernética de segundo orden y abordaje a la familia en la universidad Pontificia Bolivariana. Revista de la facultad de Trabajo Social 14 (1), 30-47.

Federación Internacional de Trabajo Social (2014). Definición de Trabajo Social Mundial. Recuperado de: https://www. ifsw.org/what-is-social-work/global-definition-of-social-work/

Fernández, G. (2009). La Formación del Sujeto Político Aspectos más sobresalientes en Colombia. Tesis doctoral, Uni- versidad Nacional De Colombia. Recuperado de: http:// www.bdigital.unal.edu.co/1943/1/16798482.2009.pdf

Gómez, L. (2010). Un espacio para la investigación documental. Revista Vanguardia Psicológica Clínica Teórica y Práctica, 1(2), 226-233.

Guerra, Y. (2017). Trabajo Social: fundamento y contemporaneidad. Buenos Aires, Argentina: Colegio de Trabajadores Sociales de la Provincia de Buenos Aires.

Huici, V., Dávila, A. (2016). Del Zoon Politikón al Zoon Elektronikón. Una reflexión sobre las condiciones de la socialidad a partir de Aristóteles. Política y Sociedad, 53 (3), 757-772.

lamamoto, M. (2003). El servicio social en la contemporaneidad Trabajo y formación profesional. Brasil: Cortez Editora.

Jiménez, W. (2012). El concepto de política y sus implicaciones en la ética pública: reflexiones a partir de Carl Schmitt y Norbert Lechner. Revista del CLAD Reforma y democracia 53 (2), 215-238.

Kisnerman, N. (1998). Pensar el Trabajo Social, una introducción desde el construccionismo. Argentina: Grupo Editorial Lumen.

López, S,. Flores, M. (2009). El fracaso del neoliberalismo y la alternativa educativa latinoamericana. Educere 47 (3), 1063-1071.

Malagón, E. (2012). Fundamentos de Trabajo Social. Bogotá, Colombia: Universidad Nacional de Colombia.

Marín, A. y Aguirre, S. (2013). sentidos y significados del movimiento de la reconceptualización del Trabajo Social en las unidades académicas de Caldas y Cundinamarca en Colombia. Revista Eleuthera 9 (2), 211-235. Recuperado de: http://eleuthera.ucaldas.edu.co/downloads/Eleuthera9_12.pdf

Martínez, M. (2008). Redes pedagógicas: la constitución del maestro como sujeto político. Colombia: Cooperativa Editorial Magisterio.

Martínez, E. y Vargas, M. (2002). La investigación sobre la educación superior en Colombia. Un estado del arte. Bogotá, Colombia: ICFES.

Netto, P. (2003). Cinco notas a propósito de la "cuestión social". Borgianni, E., Guerra, Y., y Montaño, C.(Orgs.) Servicio social crítico. Hacia la construcción del nuevo proyecto ético-político profesional (pp. 43-55). Brasil: Cortez Editora.

Netto, J. (2017). Trabajo Social: Crítica de la vida cotidiana y Método en Marx. Buenos Aires, Argentina: Colegio de Trabajadores Sociales de la Provincia de Buenos Aires. 
Pachón, D. (2016). Crítica, psicoanálisis y emancipación: el pensamiento político de Herbert Marcuse. Bogotá, Colombia: Universidad Santo Tomás.

Palma, D. (1977). La reconceptualización. Una búsqueda en América Latina. Argentina: ECRO

Parra, G. (2003). La construcción de espacio profesional desde una perspectiva histórica: desde los orígenes de la profesión al Movimiento de Reconceptualización. Un aporte a los desafíos contemporáneos. En Fernández, S. El Trabajo Social y la cuestión social: crisis, movimientos sociales y ciudadanía (pp. 79-96). Argentina: Espacio Editorial.

Pereira, P. (2003). Cuestión Social, Servicio Social y derechos de ciudadanía. En Borgianni, E; Guerra, y Montaño, C. Servicio Social Crítico. Hacia la construcción del nuevo proyecto ético-politico profesional, 56-70. Brasil: Cortez Editora

Romero, A., Casal, G. y Contreras, T. (2017). Repensar la ética en Trabajo Social desde una perspectiva de género. Cuadernos de Trabajo Social, 30(1), 51-64. DOI: https:// doi.org/10.5209/CUTS.53959

Quintero, S. (2014). El "Método Caldas" y la reconceptualización del Trabajo Social. Eleuthera 10 (1), 182-203. Recuperado de: http://eleuthera.ucaldas.edu.co/downloads/ Eleuthera10_11.pdf

Quintero, S. (2018). Contexto, tendencias y actores de la Reconceptualización. Eleuthera 20 (2), 179-198. DOI: 10.17151/eleu.2019.20.10.
Samperio, E., De Marinis, M. y Verón, J. (2004). El proceso de Reconceptualización en Trabajo Social y su relación con la sistematización de prácticas sociales. El aporte del pensamiento sociológico. VI Jornadas de Sociología. Facultad de Ciencias Sociales, Universidad de Buenos Aires, Buenos Aires. Recuperado de: http://cdsa.aacademica.org/000-045/21.pdf

Soto, O. (2012). Teologías de la liberación y movimientos sociales: Matrices de pensamiento crítico y articulaciones contrahegemónicas en la América Latina reciente, a partir del proceso social brasilero. Revista digital de historia y arqueología desde El Caribe 17 (3), 156-171. Recuperado de: http://rcientificas.uninorte.edu.co/index.php/memorias/rt/printerFriendly/4658/3782

Torres, A. (2013). El retorno a la comunidad: problemas, debates y desafíos de vivir juntos. Colombia: CINDE.

Torres, A. (2017). Prácticas educativas en movimientos sociales de América Latina. Folios 46 (2), 3-14.

Valencia, M. (2014). "Cuestión social", intervención profesional y proyecto ético-político. Triada para pensar las formas de consolidación de una teoría y práctica crítica para el Trabajo social colombiano. Eleuthera 10 (1), 99-120. Recuperado de: http://eleuthera.ucaldas.edu.co/downloads/Eleuthera10_7.pdf

Vélez, O. (2003). Reconfigurando el Trabajo Social. Perspectivas y tendencias contemporáneas. Buenos Aires, Argentina: Espacio Editorial.

Zibechi, R. (2010). América Latina: Contrainsurgencia y pobreza. Bogotá, Colombia: Ediciones Desde Abajo. 